\title{
The Shield Machine Power Supply System Based on SVG + FC Compensation Device
}

\author{
Lin Chen and Tiejun $\mathrm{Wu}$ \\ The Electrification Company of CCCC Tunnel Engineering Co., Ltd. Beijing, 100088
}

\begin{abstract}
Shield machine is the large electrical equipment in the tunnel construction, the power quality is directly related to the construction safety and economic benefits of the project, aiming at the shield equipment on Power Grid Reactive Power impact situation, serious harmonic pollution, this paper designs the static var compensator hybrid compensation scheme SVG + fixed capacitors FC the composition of the scheme and the reactive power compensation and harmonic control. By introducing basic principle and method of the control and compensation capacity and combining MATLAB simulation, the feasibility of SVG+FC compensation scheme is verified.
\end{abstract}

Keywords-shield machine; power quality; reactive power; harmonic pollution; SVG+FC

\section{INTRODUCTION}

With the development of urban rail transit, the use of shield machines is increasing, its large number of electrical equipment and electricity consumption in the construction process according to the needs of the scene from the frequent Stop, which caused a large bus to the impact of reactive power, while the frequency converter and other non-linear load to the grid to bring serious harmonic pollution ${ }^{[1]}$.

In view of the current shield machine power supply system is facing poor power quality, low power factor. Based on the actual situation of shielded machine power supply system, this paper presents a hybrid compensation method based on static combination generator SVG (Static Var Generator) + FC (Fixed Capacitor) SVG compensation principle.

\section{The Current Situation OF The Power Supply System OF SHIELD MACHINE}

Shield equipment of the knife dish propulsion system, segment assembling system, circulatory system, processing equipment work mostly need motor drive, ac motor is inductive load, the perceptual load is up and running to absorb a large number of reactive power on the grid, due to the limitations of the shunt capacitance compensation mode, for shield construction machine such complex compensation effect is not very ideal, on the other hand, the knife dish propulsion system using the nonlinear load, the frequency converter makes a lot of harmonic current into the power grid, including five times harmonic particularly prominent, cause serious harmonic pollution to power grid ${ }^{[2]}$.

\section{POWER Supply System OF SHIELD MACHINE COMPENSATION SCHEME}

\section{A. The Determination of Compensation Scheme}

SVG and SVC is the mine power supply system is widely used in compensation technology, the operation condition of the power supply system of shield machine is similar to mine, table I is the comparison of two types of compensation performance [3]

TABLE I. SVG AND SVC PERFORMANCE COMPARISON

\begin{tabular}{ccl}
\hline Performance & SVC & SVG \\
\hline Output capacity & Only output inductive or capacitive \\
reactive & \multicolumn{1}{c}{$\begin{array}{l}\text { From inductive reactive to capacitive reactive } \\
\text { continuously adjustable }\end{array}$} \\
responding speed & $2 \sim 3$ weeks $(40 \sim 60 \mathrm{~ms})$ & 10ms or less \\
Harmonic characteristics & $\begin{array}{l}\text { Harmonic characteristics of poor, their } \\
\text { own harmonic, belonging to the } \\
\text { harmonic source, to be configured filter } \\
\text { branch filter itself harmonic }\end{array}$ & $\begin{array}{l}\text { Reactive current will not be affected by changes } \\
\text { in voltage }\end{array}$ \\
\hline
\end{tabular}

Comprehensive comparison and SVG in regulating range, response speed, the performance of the harmonic characteristic and resonance problem is better than SVC. The Basic Principle of SVG and Control Mode.

1) The basic principle of SVG

The basic principle of SVG is by changing the phase bridge type circuit of the drive pulse PWM to control the amplitude and phase of output voltage in dc side, thus indirectly change the grid and dc side voltage difference, the reactor issue or absorb reactive power to the grid, realize compensation ${ }^{[4]}$. The basic principle of SVG diagram and related voltage current phasor diagram below figure 1 (a), 1 (b). 


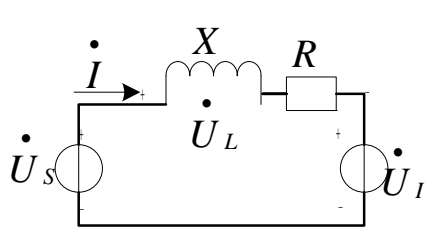

(a) The equivalent circuit of SVG

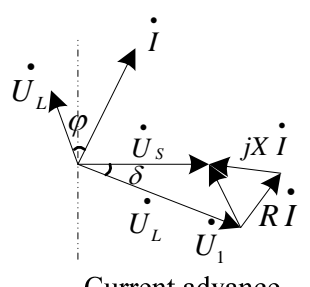

Current advance

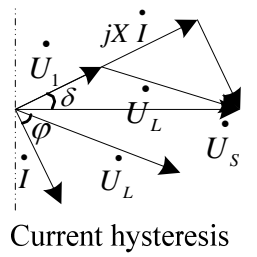

(b) UI phasor diagram

FIGURE I. SVG EQUIVALENT CIRCUIT AND PHASOR RELATIONSHIP OF UI

\section{2) SVG control mode}

SVG based on dq coordinate transformation of voltage decoupling of the outer ring, internal ring current double closed loop PI control strategy ${ }^{[5]}$. The principle block diagram is shown in figure 2:

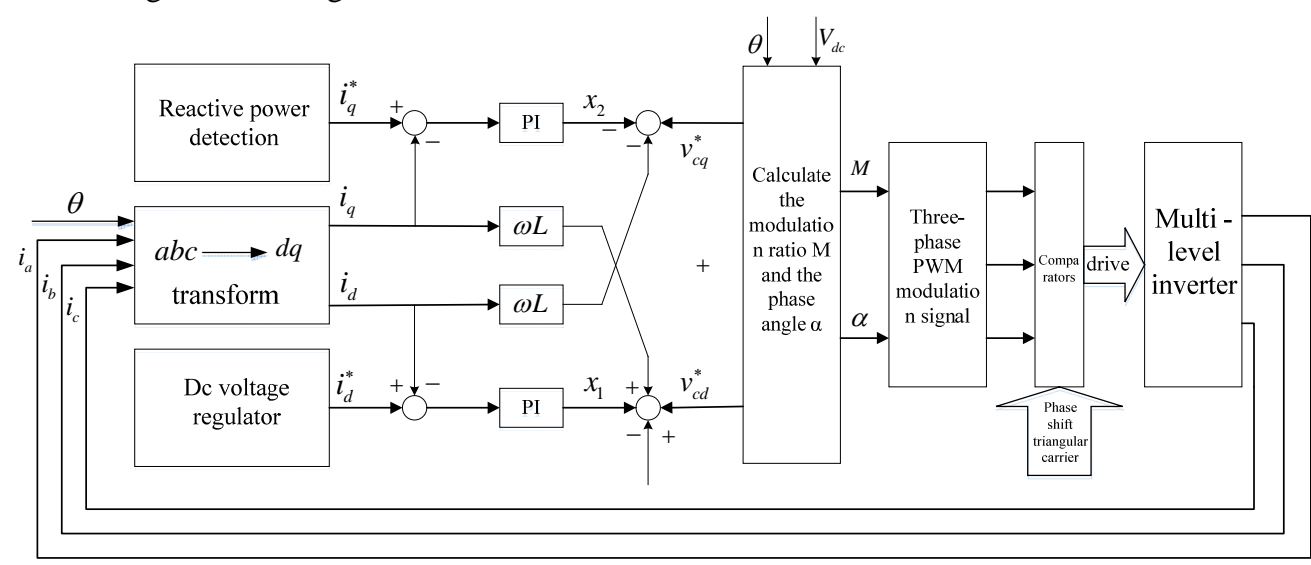

FIGURE II. THE PRINCIPLE BLOCK DIAGRAM

Load voltage synchronization signal is composed of $U_{s a}$, $U_{s b}$ and $U_{s c}$ by phase lock, $I_{c a}, I_{c b}, I_{c c}$ by Park transformation to $i_{d}$ and $i_{q}$. Reactive current reference value of $i_{q}^{*}$ is obtained by to test the $i_{L a}, i_{L b}, i_{L c}$, active current reference value of $i_{d}^{*}$ is done by $V_{d c}^{*}$ and $U_{d c}$ contrast and is obtained by PI regulating. The actual current and reference current after decoupling control can get SVG modulation signal $\mathrm{M}$ and $\alpha$.The formula is as follows (1):

$$
\left\{\begin{array}{l}
V_{c q}^{*}=V_{s q}+\left(k_{p}+\frac{k_{i}}{s}\right)\left(i_{q}^{*}-i_{q}\right)+\omega L i_{q} \\
V_{c d}^{*}=V_{s d}+\left(k_{p}+\frac{k_{i}}{s}\right)\left(i_{d}^{*}-i_{d}\right)+\omega L i_{d}
\end{array}\right.
$$

The command signals $V_{c q}^{*}$ and $V_{c d}^{*}$ are obtained from the above equation, and then through the calculation can be obtained PWM modulation signals $\mathrm{M}$ and $\alpha$, finally through the comparator to do comparison to get driven SVG inverter drive pulse.

B. Structure of $S V G+F C$

SVG + FC structure shown in Figure 3.

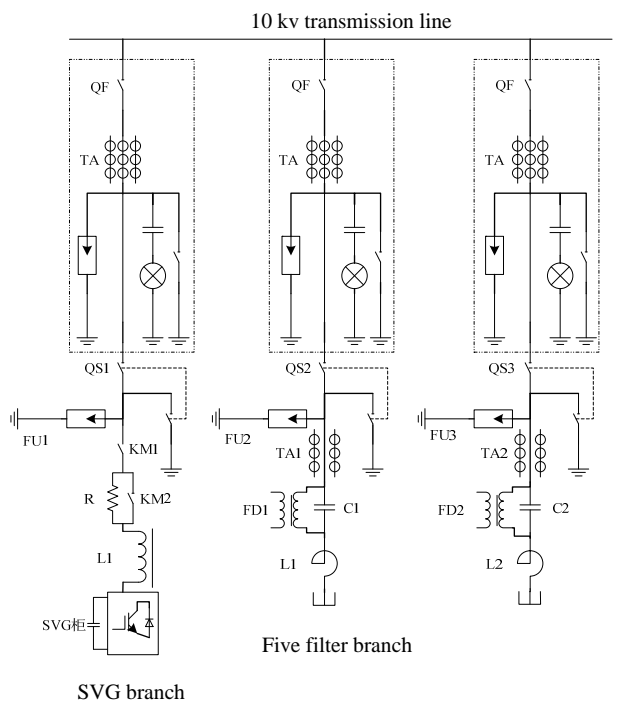

FIGURE III. STRUCTURE OF SVG + FC

\section{CALCULATION OF COMPENSATION CAPACITY AND FC PARAMETER DESIGN}

A. Calculation of Compensation Capacity

The following shield tunnel operation as an example, different operating mode and different load the power output of 
the shield machine is shown in Table II and Table II:

TABLE II. POWER PARAMETERS AT FULL LOAD

\begin{tabular}{lcccc}
\hline & $S$ & $Q$ & $G$ & $\operatorname{COS} \theta$ \\
\hline Driving mode & 13982.64 & 3982.49 & 809.23 & 0.958 \\
Assembly mode & 4141.02 & 1834.28 & 0 & 0.897 \\
\hline
\end{tabular}

TABLE III. THE POWER PARAMETERS WHEN LOAD IS 50\%

\begin{tabular}{ccccc}
\hline & $S$ & $Q$ & $G$ & $\operatorname{Cos} \theta$ \\
\hline Driving mode & 15032.4 & 6820.1 & 809.23 & 0.8912 \\
Assembly mode & 5061.97 & 3450.2 & 0 & 0.7322 \\
\hline
\end{tabular}

Assuming that the capacity after compensation is $Q_{1}$, the capacity before compensation is $Q_{2}$, the total capacity of compensation is $Q, \cos \theta_{1}$ and $\cos \theta_{2}$ are the power factor before and after compensation, respectively. The compensation capacity is calculated as follows:

$$
\begin{gathered}
Q=Q_{1}-Q_{2} \\
Q=P * \tan \theta \\
\cos \theta=P / S \\
Q=\left(\tan \theta_{2}-\tan \theta_{1}\right) * P
\end{gathered}
$$

If $\cos \theta_{2}$ value of 0.95 , the table 2, 3 data into the above formula can be calculated under the different output power of the shield machine need to compensate the reactive capacity $Q$, calculated by the shield machine in the tunneling mode, the load is $50 \%$ Of the required compensation for the maximum reactive capacity of $2457 \mathrm{Kvar}$. Taking into account the SVG should be sufficient wide compensation range, so the SVG capacity to take 2.5Mvar.

\section{B. FC Parameter Calculation}

FC filter device works is the circuit of the series resonant, when tuned in a particular harmonic frequency, the series equivalent reactance for the low impedance value, the harmonic performance for the low impedance, and thus absorb the harmonic current, So that it is not injected into the grid. In addition FC can also compensate for a certain emotional reactive power, you can increase the SVG + FC compensation range. Applicable to the shield machine power supply system conditions of the filter device mainly to 5 single-tuned filterbased. Under the ideal conditions, the parameters of the FC device are calculated as follows:

\section{1) The calculation of capacitor voltage rating}

If the maximum voltage of the grid is $U_{1 m}$, the rated voltage of the capacitor is $U_{C 1}$, then the rated voltage is calculated as follows:

$$
U_{C 1}=\frac{n^{2}}{n^{2}-1} \times U_{1 m}
$$

So the filtering circuit capacitor voltage of 5 times:

$$
U_{c 1}=\frac{5^{2}}{5^{2}-1} \times \frac{10 \times 1.1}{\sqrt{3}}=6.62
$$

Considering the harmonic current 5 times have a lifting effect on voltage, therefore get rated voltage.

\section{2) Capacitor capacity and rated current calculation}

The heat should be within the allowable range, that is, when satisfied $Q_{C N}=Q_{C 1}+Q_{C h}$, the capacitor can work for a long time, so the monotonic harmonic capacitor capacity is calculated as follows:

$$
\begin{gathered}
Q_{c}=\frac{3 U_{C N}^{2} \times I_{h}}{\sqrt{h} \times \sqrt{U_{C N}^{2}-\left(\frac{h^{2}}{h^{2}-1} \bullet \frac{U_{1 m}}{\sqrt{3}}\right)^{2}}} \\
L_{L h}=\frac{Q_{c h}}{3 U_{c N}}
\end{gathered}
$$

The system is mainly 5 harmonics, so $\mathrm{h}=5 U_{1 \mathrm{~m}}$ take 1.1 times the grid voltage. By calculating $Q_{c}=350 \mathrm{kvar}$, $L_{L h}=87$ A .

\section{3) Capacitance reactor calculation}

Capacitance of each phase capacitor

$$
X_{c h}=\frac{3 U_{C N}^{2}}{Q_{c h}}
$$


Reactance of series reactors $X_{L h}=\delta X_{C h}$

$$
L_{h}=\frac{X_{L h}}{2 \pi f}
$$

Rated capacity of the reactor $S_{L h}=3 I_{L 5}^{2} X_{L 5}$

By the formula (9) - (12), $X_{c h}=90 \Omega X_{L h}=1.4 \Omega$.

\section{SYSTEM SIMULATION}

In order to verify the compensation effect of SVG + FC compensation system designed in this paper, the control strategy of the system is simulated by Simulink environment under MATLAB software. The SVG + FC compensation system is mainly based on the system power factor and harmonic current. The validity of the verification. The simulation results are shown in Figure 4 and Figure 5.

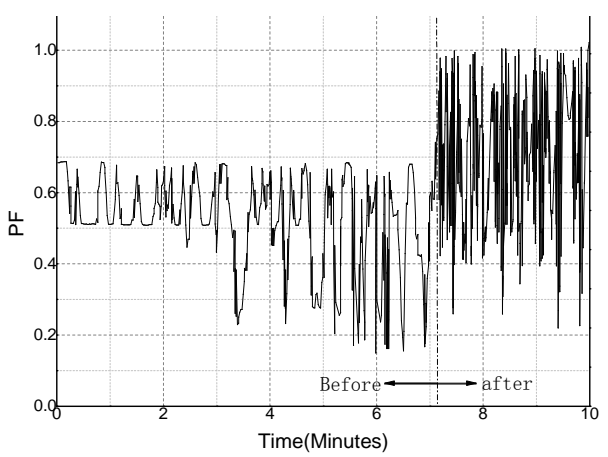

FIGURE IV. SVG BEFORE AND AFTER THE INPUT POWER FACTOR CURVE

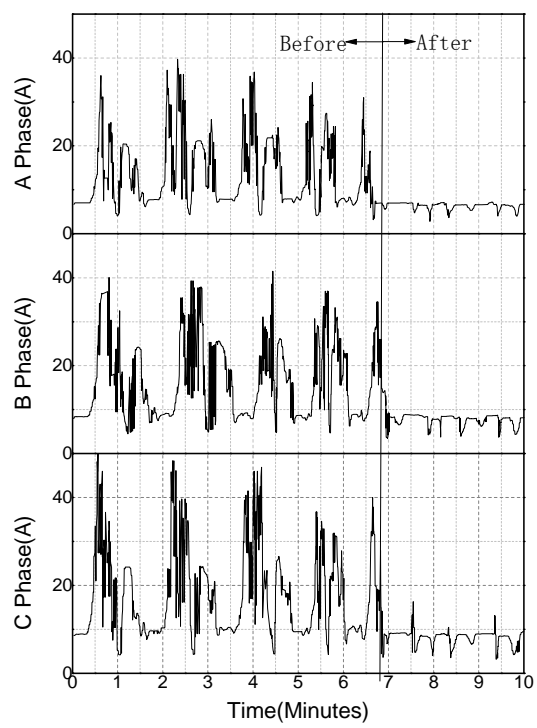

FIGURE V. SVG BEFORE AND AFTER THE FIFTH HARMONIC CURRENT DISTRIBUTION CURVE

It can be seen from the simulation diagram that the power factor of the system before SVG + FC is less than 0.7 , and the power factor rises to 0.95 after the system is put into the system.
Before the compensation device is installed, the harmonic current of the 5th harmonic reaches 50A, Harmonic current greatly reduced, basically within $10 \mathrm{~A}$. In summary, the input of SVG + FC device greatly improves the system power factor, improves the pollution of the power grid and improves the power quality of the shield machine power supply system.

\section{CONCLUSION}

In this paper, a compensation scheme is proposed for the shield machine power supply system using the static reactive power compensation device (SVG) and the FC filter. According to the control mode and control principle of the device, the compensation system is simulated and analyzed. SVG + FC combination of compensation device investment not only significantly improve the system power factor, but also in the suppression of harmonics also have a good effect. So the device can be a good solution to the current shield machine power supply system problems.

\section{REFERENCES}

[1] LI Shen-shan,XU Ming-zhu,MA Li-ming. Analysis on Design of Electrical System of Shield Tunneling Machine[J]. Road Machinery \& Construction Mechanization, 2009, 26(12):77-79 .(in Chinese)

[2] WU Yu-peng,CAI Qi-zhong,TANG Rao. Earth pressure balance shield electrical security protection of application analysis[J].Journal of GuangXi University of Science and Technology, 2011, 22(2):6-9. (in Chinese)

[3] LIU Wen-wei. The coal mine power supply system dynamic reactive power compensation technology research[J]. Coal Mine Modernization, 2010(4):83-84. (in Chinese)

[4] CHEN Hui-feng,FENG Gao-ming. Comparative Study on Dynamic Reactive Compensation Technology of Coal Mine Power Supply System[J]. Electrotechnical Application, 2008, 27(24):27-29. (in Chinese)

[5] ZANG Li-feng. The reactive power compensation and filtering system based on SVG[J]. Science \& Technology Information, 2011(1):130-132. (in Chinese) 